\title{
SIMULATION OF THERMAL PHENOMENA ON THE INTERFACE MOLTEN POLYMER/POWDER POLYMER DURING ROTATIONAL MOLDING
}

\author{
A. Tcharkhtchi ${ }^{1}$, E. Perrot ${ }^{1}$, F. Chinesta ${ }^{2}$ \\ ${ }^{1}$ LTVP (Laboratoire de Transformation et Vieillissement des Plastiques) \\ ${ }^{2}$ LMSP (Laboratoire de Mécanique de Systèmes et des Procédés) \\ UMR 8106 CNRS-ENSAM-ESEM \\ ENSAM Paris, 151 Boulevard de l'Hôpital, F-75013 Paris, France. \\ e-mail address: abbas.tcharkhtchi@paris.ensam.fr
}

\begin{abstract}
In order to simulate the heat transfer phenomenon during rotational molding an alternative approach for the melt front treatment has been used. It was considered that a polymer particle adheres to the inner mould wall or to the polymer layer when the temperature reaches the melting point of polymer. The result of this alternative adhesion of new particles on molten polymer layer is the progress of melt front until all of particle are added to the inner surface of the polymer in the mold.

The simulation was based on an explicit finite volumes scheme which, allows to proceed with a fixed mesh of the whole domain. A numerical test, then, has been performed to illustrate the capabilities of the proposed model. The results of this numerical test showed the temperature evolution of external mold surface, in the molten polymer layer and on the interface molten polymer layer - air/polymer mixture region. These results have been then interpreted.
\end{abstract}

Key words : rotational molding, simulation, heat transfer 


\section{INTRODUCTION}

Rotational molding is a technique for industrial hollow and complex parts manufacturing (1-7). It is one of the most versatile molding processes since the plastic (polymer) revolution. The adaptability of this process for manufacturing articles having variety of shapes, sizes and colors have made the process very fast growing and hence rotational molding is replacing many other traditional manufacturing processes. The molding process consists of four main stages, illustrated in figure 1:

1. Mold loading: A charge of polymer powder is placed in one half of a mold, which is then closed. The well ground quantity of plastic powder has to be pre-determined to produce the desired shape of desired thickness. This quantity can be determined by using the following relationship: $M_{p}=\rho_{p s} L_{p} S$ (see the nomenclature at the end of the paper).

2. Mold rotation and heating: The rotating mold is then inserted into the oven, where the polymer is heated up to its melting point. At this temperature, the powder inside the mould starts to melt and coat the inner surface of the mold. By increasing the temperature, all the polymer will be molten. When the polymer is fluid enough, it will be distributed homogeneously on the mould surface, because its biaxial rotation.

3. Mold cooling: In this stage, the arm with the rotating mould is transferred to a cooled chamber, where air, water or a combination of both, are used to cool the mould and the molten polymer. The cooling process continues until the product is rigid enough.

4. De-molding of the final product: After the cooling, the rotational arm is transferred to the load-unload station. The mould is opened and the product is de-molded. To make easy the demolding operation, it is necessary to coat the inner mould surface with a very thin layer of a demolding agent before the introduction of the polymer powder. 


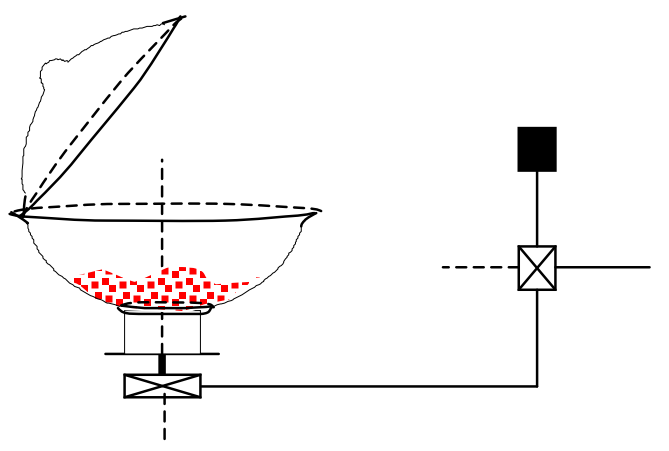

Loading

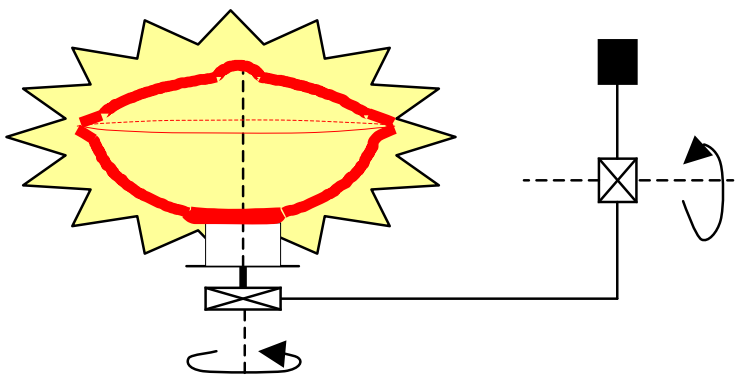

Cooling

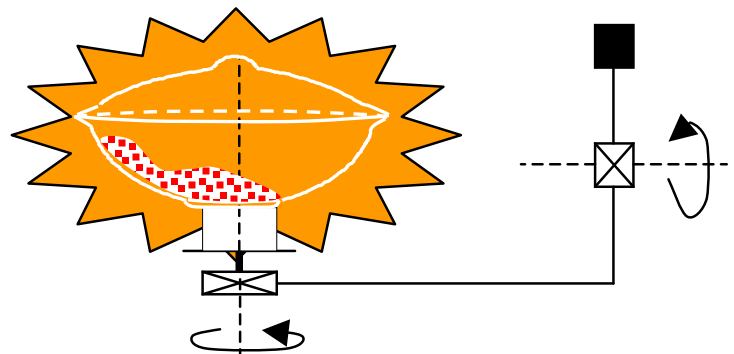

Heating

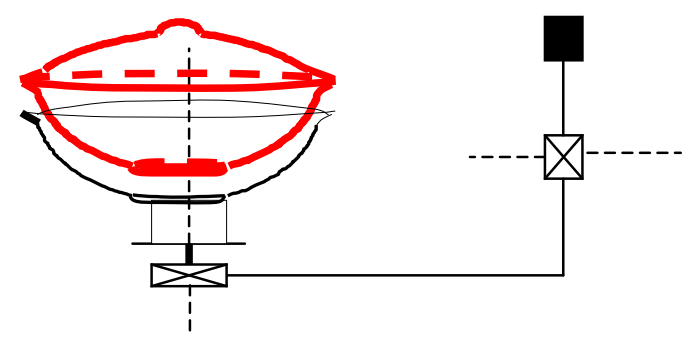

Demolding

Figure 1 - Different steps of rotational molding

Different advantages of rotational molding are the following:

- The moulds used for this technique are simple and relatively cheap. Indeed, rotational molding is a low-pressure process and as a consequence, high strength moulds are not required.

- There is not a significant residual stress in the rotomolded part.

- Moulds of different sizes and shapes may be run simultaneously in the same equipment.

- This process is particularly suitable for multi-layer parts manufacturing as well as for polymer foams processing.

- Plastics or metal inserts can be inserted easily inside the manufactured part without any cut.

- Parts show a uniform wall thickness. 
- There are no weld lines induced by processing.

- Good surface details and gloss can be obtained.

- Full charge of polymer is normally consumed, reducing material wastes.

Being its main limitations:

- Molding cycles are long compared to other processes, especially in multi-layer parts.

- Materials suited to the rotational molding process are limited. At present, polyethylene accounts for about $90 \%$ of the materials used. However, the range of suitable materials is increasing due to continual research.

- The risk of polymer degradation during process is high. It is necessary to stabilize the polymer with efficient and specific stabilizers.

- Polymer must be ground to a fine powder, which increases the material costs.

The main parameters involved in rotational molding processes are: (i) the oven temperature; (ii) the heating and cooling times; (iii) the rotation velocity around both axes; (iv) the polymer properties, like its nature, molecular weight, powder dimensions, ... and (v) the mould characteristics: material, size and geometry.

The polymer physical characteristics change during the rotational molding. Usually, the polymer powder is thermoplastic with a mean grain diameter of $100-500 \mu \mathrm{m}$. Those changes can be shown in the time-temperature diagram which provides very valuable information about the different physical states of the polymer (Figure 2). In general, one can distinguish 4 different stages:

1. At the start of the cycle, the mould and the polymer are cold and the powder tumbles freely. The heat is transferred from the mould towards the air and powder mixture. 
2. At point "A" in figure 2, the first layer of polymer adheres to the mould. The slop reduction in the temperature evolution curve is due to the energy absorption of the melting processes.

3. At point "B", all the powder has been molten. The thermal energy continues to decrease the polymer viscosity. Between "B" and "C", the homogenization of the bend takes place and air bubbles disappear (the density increases). The inner surface of the molten polymer layer becomes smooth.

4. When the mould, still in rotation, is moved into the cooling chamber, the temperature decreases continuously up to point " $D$ ". From " $D$ " to "E", there is a change of temperature evolution slope corresponding to the solidification. Finally at point $\mathrm{F}$ the part can be demolded.

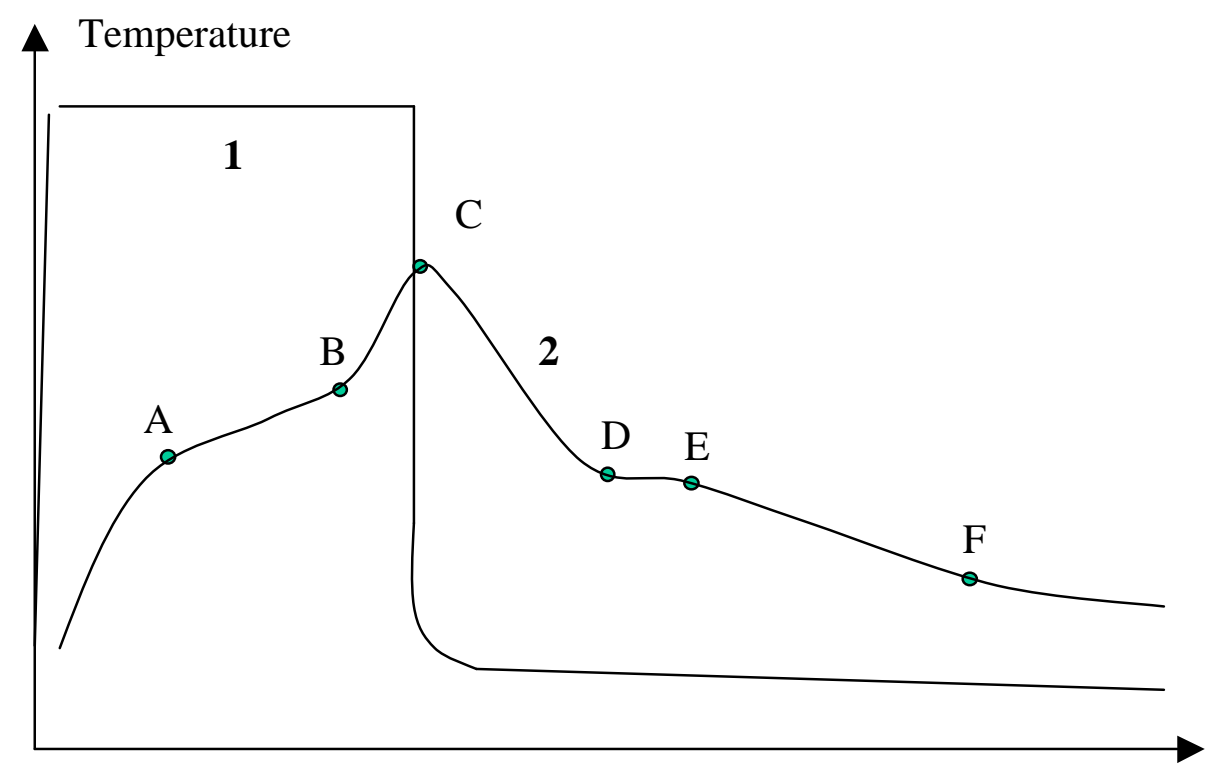

Time

Figure 2 - Temperature-time diagram

1) oven 2) in the mould 
The heat transfer during rotational molding is a complex phenomenon based in an unsteady-state heat transfer. For the simulation of this process, it is necessary to take into account:

- the heat transfer from the oven ambient towards the external mould wall;

- the heat transfer in the mould;

- the heat transfer at the interface between the mould and the molten polymer layer;

- the heat transfer in the molten polymer layer whose thickness increases in time;

- the heat transfer at the interface between the molten polymer layer and the powder polymer/air mixture.

Many thermal numerical approaches concerning the rotational molding exist, each one involving a certain number of simplifying hypotheses (8-9). One of the pioneer in this field was Throne (10) who proposed a heat transfer model in which the powder is assumed to be in static contact with the mould surface at all times. In this form the heat transfer equation was solved in both domains (metal and polymer) by imposing the appropriate continuity conditions on the interface. Sun and Crawford (11-12) assume a static situation because it is argued that the slow rotation velocity of the mould sits the polymer powder in the lowermost part of the mould. The powder particle size effects were also analyzed. A more complex model was proposed by Gogos et al. (13) which assumes the powder well-mixed. In this model the powder temperature remains spatially uniform, evolving in time. In this work, the authors assume that the melt front evolves according to the Stefan condition: the discontinuity in the heat flux across the interface induces the growth of the molten plastic layer. However, the melt front was assumed to be located at the interface between the molten polymer and the powder/air mixture regions. In consequence, the case of a melt front progressing within a polymer grain was not contemplated. 
In the present work we propose an alternative approach for the melt front treatment. In our approach we consider that a polymer grain adheres to the mould surface (or to the molten polymer layer) when its inner surface reaches the melting temperature. But now, the melt front progresses within the just adhered grain, and when it reaches the other boundary a new grain is added to the molten polymer layer. In this form the powder fusion progresses until its complete melting.

In order to simulate this process, an explicit finite volumes scheme will be applied, which, as proved later, allows to proceed with a fixed mesh of the whole domain. In order to avoid the difficulties related to the change of phase accounting, an enthalpy formulation will be used. To describe easily the explicit strategy, which will considered in this work for simulating rotational molding, we consider the one-dimensional heat transfer problem defined in the interval $[0, \mathrm{~L}]$, where $N$ nodes uniformly distributed are considered (defining the enthalpy and temperature of their associated volumes, both assumed constant within each finite volume), and the temperature is prescribed at both boundaries $T(x=0, t)=T_{0}$ and $T(x=L, t)=T_{L}$ with $T_{0}<T_{f}<T_{L}$, as well as at the initial time $T(x, t=0)=T^{0}$. The enthalpy $H$ is defined by:

$$
H(T)= \begin{cases}\int_{T_{r e f}}^{T} \rho_{p s .} C_{p s .} d T & \text { if } T<T_{f} \\ \int_{T_{f}} \rho_{p s} . C_{p s .} d T+\Delta H_{f}+\int_{T_{f}}^{T} \rho_{p l} . C_{p l .} d T & \text { if } T>T_{f}\end{cases}
$$

where the index $s$ and $l$ are used to identify the solid and liquid phases respectively, $\Delta H_{f}$ represents the fusion enthalpy (that is introduced in the model due to the fact that the by far most common materials used for rotational molding are semi-crystalline polymers) and $T_{r e f}$ a reference temperature. The general expression of the heat equation, taking into account eventual phase changes, results: 


$$
\frac{\partial H}{\partial t}+\operatorname{div}(\operatorname{kgrad} T)=0
$$

with the temperature-enthalpy relation given by Eq. (1). Now, we can consider a mesh of the domain, which consists of $N$ nodes uniformly distributed. From the initial temperature known at $t=0$ the initial enthalpy of the internal nodes can be computed at that time using Eq. (1). Thus, from the discretisation of Eq. (2)

$$
\frac{H_{i}^{n+1}-H_{i}^{n}}{\Delta t}-\frac{k_{i+1 / 2}^{n} \frac{T_{i+1}^{n}-T_{i}^{n}}{h}-k_{i-1 / 2}^{n} \frac{T_{i}^{n}-T_{i-1}^{n}}{h}}{h}=0, \forall \mathrm{i} \in[2, \cdots, \mathrm{N}-1]
$$

we can update the enthalpy. In Eq. (3) the superscript refers to the time step considered, i.e. $t_{n}=n \Delta t ; h=L /(N-1), \quad k_{i+1 / 2}^{n}$ is the thermal conductivity at the intermediate point between the nodes $i$ and $i+1$; and the time step $\Delta t$ depends on the mesh size $h$ to guarantee the integration scheme stability. Now, from the enthalpies just computed, the nodal temperatures can be updated using Eq. (1):

Find $T_{i}^{n+1} \quad \forall i \in[2, \cdots, N-1]\left(T_{1}^{n+1}=T_{0}\right.$ and $\left.T_{N}^{n+1}=T_{L}\right)$ from

$$
\begin{cases}H_{i}^{n+1}=\int_{T_{r e f}}^{T_{i}^{n+1}} \rho_{p s} . C_{p s .} d T & \text { if } \quad H_{i}^{n+1}<\int_{T_{r e f}}^{T_{f}} \rho_{p s .} C_{p s .} d T \\ T_{i}^{n+1}=T_{f} & \text { if } \int_{T_{r e f}}^{T_{f}} \rho_{p s .} C_{p s .} d T \leq H_{i}^{n+1} \leq \int_{T_{r e f}}^{T_{f}} \rho_{p s .} C_{p s .} d T+\Delta H_{f} \\ H_{i}^{n+1}=\int_{T_{r e f}}^{T_{f}} \rho_{p s .} C_{p s .} d T+\Delta H_{f}+\int_{T_{f}}^{T_{i}^{n+1}} \rho_{p l} C_{p l} d T & \text { if } \quad H_{i}^{n+1}>\int_{T_{r e f}}^{T_{f}} \rho_{p s .} C_{p s .} d T+\Delta H_{f}\end{cases}
$$

Remark 1: Semi-implicit or fully implicit formulations can be also defined, which allow higher time steps.

Remark 2: In this work we assume, for the sake of simplicity, that the phase change occurs when the temperature reaches a given temperature, despite of the phase change occurs within a temperature interval. However, this assumption does not affect to the generality of the proposed numerical approach. 
Remark 3: Eq. (4) can be applied when the thermal parameters are not constant. However, for illustrating the numerical procedure, and for the sake of simplicity, all these parameters will be considered constant in section 3 .

\section{SIMULATING ROTATIONAL MOLDING: A LAYER-TO-LAYER APPROACH}

\subsection{Computational domain, boundary conditions and thermal properties}

For simulating the thermal processes involved in rotational molding we consider the following assumptions: (i) the heat transfer is unidirectional, i.e. the heat transfer takes place in the direction of the mould thickness, and the heat fluxes in the other directions can be neglected; (ii) we can assume that the polymer layer adhered to the inner mould surface increases its thickness when its inner surface reaches the polymer fusion temperature, because at this moment a new polymer grain adheres to the polymer layer; (iii) all the thermal parameters such that the specific heat, the thermal conductivities, the latent heat, and their dependence on the temperature are assumed known; (iv) the curvature radius of the mould surface is much higher than the thickness of both the mould and the polymer layer; (v) the thickness of the polymer layer adhered to the mould is uniform enough; (vi) the temperature in the powder polymer / air mixture can be considered uniform as consequence of the high convection effects; and (vii) the heat transfer model will be assumed isotropic.

Now we assume a computational domain of length $L$ lower than the physical domain, in order to reduce the size of the air / powder polymer mixture region, with the associated reduction in the number of degrees of freedom required in the discretisation. This domain reduction is possible as soon as the thermal properties related to the modified mixture region are adjusted in order to don't alter the physical heat transfer. 
In the numerical simulations presented in the next section we will consider $L=L_{m}+2 L_{p}$ (according to the notation included in the nomenclature section). The final polymer layer thickness is obtained from the following relation

$$
L_{p}=\frac{M_{p}}{S \rho_{p s}}
$$

Effectively, during the thermal process the melt front position evolves from $L_{f}=L_{m}$ at the beginning of the process, until $L_{f}=L_{m}+L_{p}$. At the beginning a mixture of air and solid polymer powder fills the mould. During the process, the polymer fraction in the mixture decreases, vanishing when $L_{f}=L_{m}+L_{p}$. The conditions to prescribe on the domain boundaries are:

$$
\left\{\begin{array}{l}
T(x=0, t)=T_{e x t}(t) \\
\left.\frac{d T}{d x}\right|_{x=L, t}=0
\end{array}\right.
$$

where $T_{\text {ext }}(t)$ represents the oven heating curve. Moreover, an initial condition is required to start the evolution process. In our case we consider the ambient temperature everywhere, i.e.

$$
T(x, t=0)=T_{a m b}
$$

The thermal problem defined by the heat equation (Eq. (2)), the enthalpy definition and the initial and boundary conditions (Eqs. (6) and (7)), will be perfectly established as soon as the thermal properties of the mixture (powder polymer - air) occupying the pseudodomain $L_{f}<x<L$ are defined. For this purpose we consider the specific equivalent heat in the mixture pseudo-domain:

$$
\overline{\rho C}^{*}(t)=\frac{V-S\left(L_{f}-L_{m}\right)}{S\left(L-L_{f}\right)} \overline{\rho C}(t) \approx \frac{V}{S\left(L-L_{f}\right)} \overline{\rho C}(t)
$$

where the dependence on the time is due to the fact that $L_{f}=L_{f}(t)$ and both the density and the specific heat depend on the temperature that evolves in time. $\overline{\rho C}(t)$ is given by the mixture rule 


$$
\overline{\rho C}(t)=\frac{V_{p}-\left(L_{f}-L_{m}\right) S}{V-\left(L_{f}-L_{m}\right) S} \rho_{p s} C_{p s}+\frac{V-V_{p}}{V-\left(L_{f}-L_{m}\right) S} \rho_{a} C_{a}
$$

and where the total volume of polymer results $V_{p}=\frac{M_{p}}{\rho_{p s}}$.

We can prove the consistency of the previous expression computing its value for $t=0$

$$
\overline{\rho C}(t=0)=\frac{V_{p}}{V} \rho_{p s} C_{p s}+\frac{V-V_{p}}{V} \rho_{a} C_{a}
$$

and for $t \rightarrow \infty$

$$
\overline{\rho C}(t \rightarrow \infty)=\frac{V_{p}-L_{p} S}{V-L_{p} S} \rho_{p s} C_{p s}+\frac{V-V_{p}}{V-L_{p} S} \rho_{a} C_{a}=\rho_{a} C_{a}
$$

Moreover, in order to verify the assumption (vi), an artificial high conductivity is assumed in this mixture region.

\subsection{Heat transfer problem discretisation}

The computational domain is divided in $N$ elements of size $h_{x}\left(h_{x}=\frac{L}{N}\right)$. In this way, the computational domain contains $N+1$ nodes where the temperature and enthalpies will be evaluated. The position of the different nodes is denoted by $x_{i}=i h_{x}, i \in[0, \cdots N]$. Moreover, the temperature evolution is assumed linear between two consecutive nodes. We assume that for a time $t_{n}=n \Delta t$ the melt front is located at $x_{f}=L_{f}$, where by a sake of simplicity we omit the dependence of $L_{f}$ on the time. The process starts from the nodal temperatures and enthalpies known. The initial temperatures were $T_{i}^{0}=T_{a m b}, i \in[1, \cdots, N]$ and $T_{0}^{0}=T_{\text {ext }}(t=0)$ where the superscript indicates the time step and the subscript the node considered. In order to verify the boundary conditions $T_{0}^{n}=T_{\text {ext }}(n \Delta t)$ and $T_{N}^{n}=T_{N-1}^{n}, \forall n$. The initial enthalpies are computed from: 


$$
\begin{aligned}
& \text { If } i h_{x}<L_{m} \quad H_{i}^{0}=\int_{T_{r e f}}^{T_{i}^{0}} \rho_{m} C_{m} d T \\
& \text { If } i h_{x}>L_{f}=L_{m} \quad H_{i}^{0}=\int_{T_{\text {ref }}}^{T_{0}^{0}} \overline{\rho C}^{*} d T
\end{aligned}
$$

Thus, the enthalpy updating is given by:

$$
\begin{aligned}
& \text { If } i=0 \\
& \text { If } i=N \\
& \frac{h_{x}}{2} \frac{H_{i}^{n+1}-H_{i}^{n}}{\Delta t}=h_{e x t}\left(T_{e x t}^{n}-T_{i}^{n}\right)+k_{i+\frac{1}{2}}^{n}\left(\frac{T_{i+1}^{n}-T_{i}^{n}}{h_{x}}\right) \\
& \text { If } x_{i+\frac{1}{2}}>L_{f} \& x_{i-\frac{1}{2}}<L_{f} \\
& \frac{h_{x}}{2} \frac{H_{i}^{n+1}-H_{i}^{n}}{\Delta t}=-k_{i-\frac{1}{2}}^{n}\left(\frac{T_{i}^{n}-T_{i-1}^{n}}{h_{x}}\right) \\
& \Rightarrow N_{f}=i \\
& h_{x} \frac{H_{i}^{n+1}-H_{i}^{n}}{\Delta t}=h_{\mathrm{int}}\left(T_{i+1}^{n}-T_{i}^{n}\right)-k_{i-\frac{1}{2}}^{n}\left(\frac{T_{i}^{n}-T_{i-1}^{n}}{h_{x}}\right) \\
& h_{x} \frac{H_{i+1}^{n+1}-H_{i+1}^{n}}{\Delta t}=-h_{\text {int }}\left(T_{i+1}^{n}-T_{i}^{n}\right)+k_{i+\frac{3}{2}}^{n}\left(\frac{T_{i+2}^{n}-T_{i+1}^{n}}{h_{x}}\right) \\
& \text { If } i \neq 0 \& i \neq N \& i \neq N_{f} \& i \neq N_{f}+1 \\
& h_{x} \frac{H_{i}^{n+1}-H_{i}^{n}}{\Delta t}=-k_{i-\frac{1}{2}}^{n}\left(\frac{T_{i}^{n}-T_{i-1}^{n}}{h_{x}}\right)+k_{i+\frac{1}{2}}^{n}\left(\frac{T_{i+1}^{n}-T_{i}^{n}}{h_{x}}\right)
\end{aligned}
$$

Now, with the enthalpies just computed, the nodal temperatures can be updated from:

If $i h_{x}<L_{m}$

If $L_{m}<i h_{x}<L_{f}$

$$
H_{i}^{n+1}=\int_{T_{\text {ref }}}^{T_{i}^{n+1}} \rho_{m} C_{m} d T
$$

$$
\begin{array}{ll}
H_{i}^{n+1}=\int_{T_{r e f}}^{T_{i}^{n+1}} \rho_{p s} C_{p s} d T & \text { If } H_{i}^{n+1}<\int_{T_{r e f}}^{T_{f}} \rho_{p s} C_{p s} d T \\
T_{i}^{n+1}=T_{f} & \text { If } \int_{T_{r e f}}^{T_{f}} \rho_{p s} C_{p s} d T<H_{i}^{n+1}<\int_{T_{r e f}}^{T_{f}} \rho_{p s} C_{p s} d T+\Delta H_{f} \\
H_{i}^{n+1}=\int_{T_{r e f}}^{T_{f}} \rho_{p s} C_{p s} d T+\Delta H_{f}+\int_{T_{f}}^{T_{i}^{n+1}} \rho_{p l} C_{p l} d T & \text { If } H_{i}^{n+1}>\int_{T_{r e f}}^{T_{f}} \rho_{p s} C_{p s} d T+\Delta H_{f}
\end{array}
$$

If $i_{x}>L_{f}$

$$
H_{i}^{n+1}=\int_{T_{r e f}}^{T_{i}^{n+1}} \overline{\rho C}^{*} d T
$$


where the polymer phase change has been taken into account. To predict the evolution of the molten polymer layer thickness, we consider that when the node located on the inner surface of the polymer layer reaches the fusion temperature a polymer grain adheres and in consequence the polymer layer thickness increases with the value of the grain size, i.e. $L_{f}=L_{f}+h_{g}$, and the nodes located inside the new grain starts its heating process from the existing temperature in the mixture zone. At this time step, the enthalpies are updated in the polymer grain just adhered to the polymer layer (where the polymer fraction changes from the mixture region value to one) as well as in the mixture region whose polymer fraction decreases suddenly when the grain adheres to the polymer layer, in order to guarantee both the continuity in the temperature field and the energy conservation.

\section{NUMERICAL TEST}

In order to illustrate the capabilities of the proposed numerical strategy we will consider the following "non-physical" situation:

$$
\begin{aligned}
& C_{p s}=500 \mathrm{~J} \cdot \mathrm{kg}^{-1} \cdot \mathrm{K}^{-1} ; C_{p l}=1000 \mathrm{~J} \cdot \mathrm{kg}^{-1} \cdot \mathrm{K}^{-1} ; C_{m}=880 \mathrm{~J} \cdot \mathrm{kg}^{-1} \cdot \mathrm{K}^{-1} ; C_{a}=1000 \mathrm{~J} \cdot \mathrm{kg}^{-1} \cdot \mathrm{K}^{-1} ; \Delta H= \\
& 58000 \mathrm{~J} \cdot \mathrm{m}^{-3} ; h_{e x t}=20000 \mathrm{~W} \cdot \mathrm{m}^{-2} \cdot \mathrm{K}^{-1} ; h_{i n t}=10 \mathrm{~W} \cdot \mathrm{m}^{-2} \cdot \mathrm{K}^{-1} ; h_{g}=0.0003 \mathrm{~m} \cdot ; h_{x}=0.0001 \mathrm{~m} \cdot ; \\
& K_{p}=0.42 \mathrm{~W} \cdot \mathrm{m}^{-1} \cdot \mathrm{K}^{-1} ; K_{m}=150 \mathrm{~W} \cdot \mathrm{m}^{-1} \cdot \mathrm{K}^{-1} ; K_{a}=2000 \mathrm{~W} \cdot \mathrm{m}^{-1} \cdot \mathrm{K}^{-1} ; L_{m}=0.005 \mathrm{~m} \cdot ; L_{p}=0.003 \\
& \mathrm{~m} . ; T_{a m b}=398{ }^{\circ} \mathrm{K} ; T_{\text {ext }}=503{ }^{\circ} \mathrm{K} ; T_{f}=403.5^{\circ} \mathrm{K} ; \rho_{p s}=870 \mathrm{Kg} \cdot \mathrm{m}^{-3} ; \rho_{p l}=670 \mathrm{Kg} \cdot \mathrm{m}^{-3} ; \rho_{m}= \\
& 2700 \mathrm{Kg} \cdot \mathrm{m}^{-3} \text { and } \rho_{a}=1.0 \mathrm{Kg} \cdot \mathrm{m}^{-3} .
\end{aligned}
$$

Fig. 3 depicts the temperature evolution on the external mould surface, whereas that Fig. 4 illustrates this evolution in a point located inside the final molten polymer layer. 
$\mathrm{T}\left({ }^{\circ} \mathrm{C}\right)$

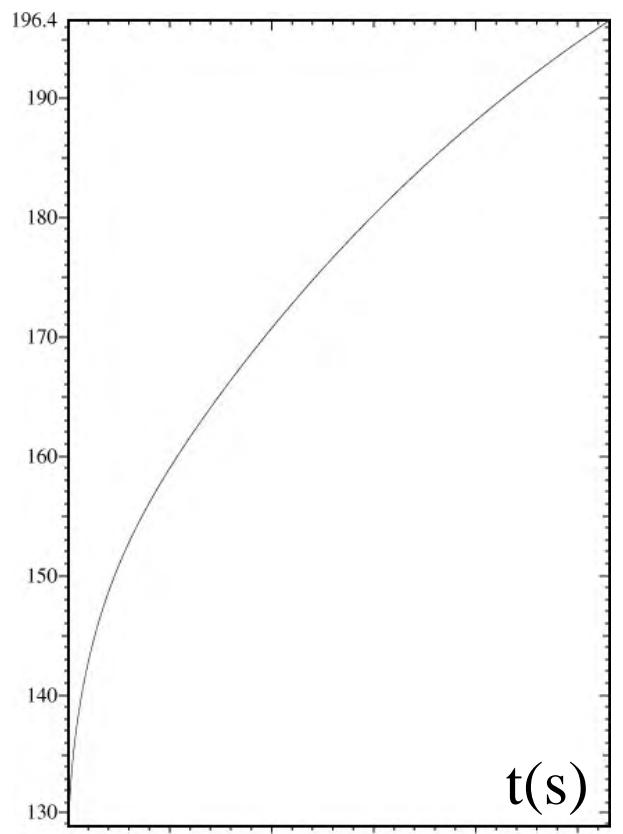

Fig. 3. Temperature evolution on the external mould surface

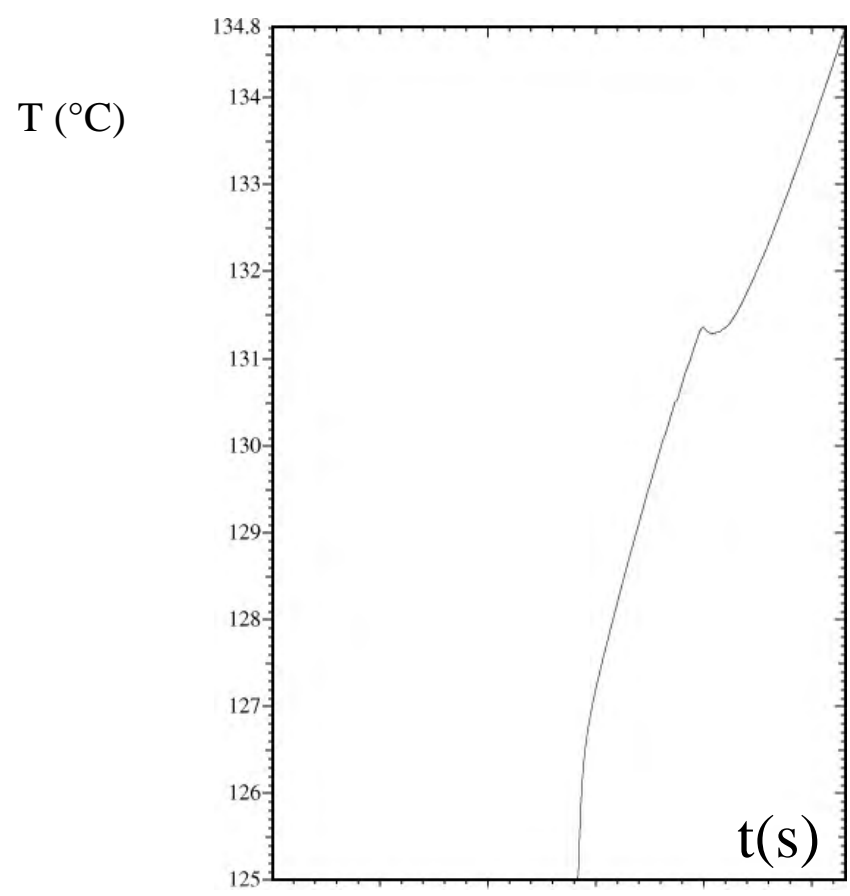

Fig. 4. Temperature evolution in the molten polymer layer

We can notice from Fig. 4, that the fact of considering a very small "non-physical" convection coefficient related to the powder/air mixture induces an unchanged constant temperature in that region. When the considered point is assumed to be part of polymer grain that have just 
adhered to the molten polymer layer, the temperature at this point increases until reaching the melting temperature $\left(130.5{ }^{\circ} \mathrm{C}\right)$. At this point there is a very small plateau (inappreciable for the polymer fusion enthalpy here considered) during the phase change of the volume containing the considered point. After, the temperature continues to grow, but we can appreciate from Fig. 4 that one degree later (around $131.5^{\circ} \mathrm{C}$ ) the considered volume is slightly cooled. In fact, at this moment a new polymer grain adheres to the polymer layer. As at this moment the temperature in the new grain is assumed to be equal to the one existing in the air-polymer powder mixture (in our case around $125^{\circ} \mathrm{C}$ due to the very small convection coefficient assumed on the polymer layer - mixture region interface) the heat flux leaving the material volume associated with the considered point increases due to the high temperature gradients induced. However, the heat flux coming to this volume does not change significantly, and in consequence the considered volume will be slightly cooled.

In Fig. 5 the temperature evolution on the interface between the polymer layer and the air/polymer mixture region is depicted. The position of this interface evolves also in time, from the inner mould surface (at the beginning of the thermal cycle) until reaching the part thickness at the end of the process. We can observe that when it reaches the phase of change temperature its position is updated one polymer grain size (a new grain is adhered) and its temperature shut down to the powder polymer/air mixture temperature. Moreover, due to the low conductivity of polymer materials, the time required to melt each polymer grain increases as the molten polymer layer increases, due to its thermal resistance. 


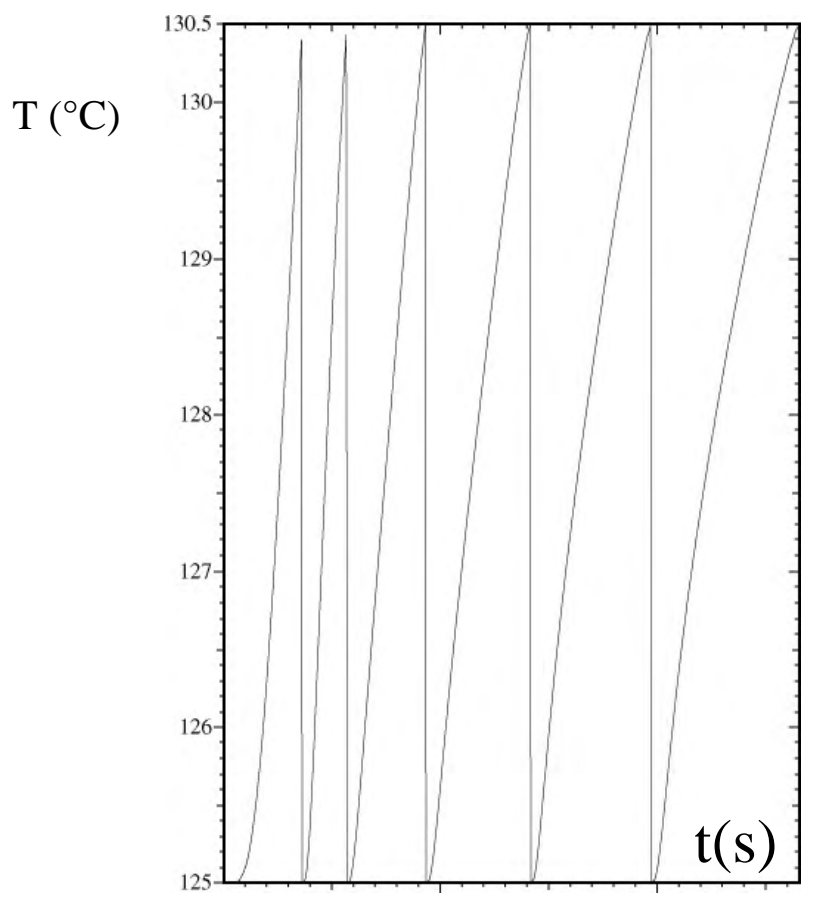

Fig. 5. Temperature $\left({ }^{0} \mathrm{C}\right)$ evolution on the interface molten polymer layer - air/polymer mixture region

\section{CONCLUSION}

This paper proposes an alternative approach to the melt front treatment during rotational molding. The melt front is described inside a single grain. The progress of the macroscopic melt front is realized by the contact and adhesion of a new grain, when the surface temperate of the first one reaches the melting temperature. The simulation was based on an explicit finite volumes scheme which, allows to proceed with a fixed mesh of the whole domain. A numerical test, then, has been performed to illustrate the capabilities of the proposed model. The model validation is a work in progress, out of the aim of the present paper.

\section{REFERENCES}


1) R. J. Crawford, "Rotational Moulding of Plastics", Progress in rubber and plastics technology, , Vol. 6 , N 1 , pp. $1-29$ (1990)

2) C. B. Guobin Liu, C. B. Park, J. A. Lefas, "Production of Low-density LLDPE Foams in Rotational Molding” Polymer Engineering and Science, , Vol 38 , $\mathrm{N}^{\circ} 12$, pp. 1997 - 2009 (1998)

3) E. H. Wang Xin, E. H. Harkin-Jones, R. J. Crawford, A. M.Fatnes, "Rotational Moulding of Metallocene Polyethylenes", Plastics rubber and composites, Vol. 29 , $\mathrm{N}^{\circ} 7$, pp. $340-348(2000)$

4) A. Tcharkhtchi, P. Barcelo, Ph. Mazabraud, F. Jousse, M. Kearns, "Study of Adhesion Between two Layers in Multilayer Rotomolded Products”, Advanced engineering materials, Vol. 4 , $\mathrm{N}^{\circ} 7,475-478$ (2002)

5) R. J. Crawford, P. J. Nugent, “A New Process Control System for Rotational Moulding”, Plastics, Rubber and Composites Processing and Applications, Vol. 17, pp. 23-41 (1992)

6) P. J. Nugent, R. J. Crawford, "Process Control for Rotational Moulding", inRotational moulding of Plastcs", Edited by R. J. Crawford, John Wiley\&Sons Inc., second edition, pp 196-216 (1997)

7) S. J. Liu, C. H.Yang, "Rotational Moulding of Expanded Polyethylene by Pellets Cellular Polymers”, Vol. 19 , N 4 , pp. 257 - 270 (2000) 
8) P. J. Nugent, "A Study of Heat transfer and Process Control in the Rotational Moulding Process for Polymer Powders”, PhD Thesis, Queen's University, Belfast, Sept. 1990.

9) X. M. Wang, "Computer Simulation of the Rotational Moulding", PhD Thesis, Queen's University, Belfast, Sept. 1994

10) J.L. Throne, Rotational Molding Heat Transfer - An Update. Polymer Engineering and Science, Vol. 16, n. 4, pp. 257-264 (1976)

11) D.W. Sun and R.J. Crawford. Computer Simulation of Rotational Moulding Heat Transfer Processes. Plastics, Rubber and Composites Processing and Applications, Vol. 19, n. 1, pp. 47-53 (1993).

12) M. T. Attaran, E. J. Wright, R. J. Crawford, "Computer Modelling of the Rotational Moulding Process", SPE ANTEC, TORONTO, CANADA (1997)

13) G. Gogos, L.G. Olson, X. Liu and V.R. Pasham. New Models for Rotational Molding of Plastics. Poymer Engineering and Science, Vol. 39, n. 9, pp. 13871398 (1998).

\section{Nomenclature}

$\begin{array}{lll}C_{p s} & \text { Solid polymer specific heat } \quad \mathrm{J} \cdot \mathrm{kg}^{-1} \cdot \mathrm{K}^{-1}\end{array}$

$\begin{array}{lll}C_{p l} & \text { Liquid polymer specific heat } \quad \mathrm{J} \cdot \mathrm{kg}^{-1} \cdot \mathrm{K}^{-1}\end{array}$ 
$C_{m} \quad$ Mould metal specific heat

$\mathrm{J} \cdot \mathrm{kg}^{-1} \cdot \mathrm{K}^{-1}$

$C_{a} \quad$ Air specific heat

$\mathrm{J} \cdot \mathrm{kg}^{-1} \cdot \mathrm{K}^{-1}$

div Divergence operator

grad Gradient operator

$H \quad$ Enthalpy

$\mathrm{J} . \mathrm{m}^{-3}$

$\Delta H \quad$ Polymer fusion enthalpy

$\mathrm{J} . \mathrm{m}^{-3}$

$h_{e x t} \quad$ External hydrodynamic coefficient (owen-mould)

$\mathrm{W} \cdot \mathrm{m}^{-2} \cdot \mathrm{K}^{-1}$

$h_{\text {int }} \quad$ Internal hydrodynamic coefficient

(molten polymer layer - solid polymer and air mixture region)

$\mathrm{W} \cdot \mathrm{m}^{-2} \cdot \mathrm{K}^{-1}$

$h_{g} \quad$ Representative size of a polymer grain

$\mathrm{m}$

$h_{x} \quad$ Mesh size

$\mathrm{m}$

$K_{p} \quad$ Polymer thermal conductivity tensor

$\mathrm{W} \cdot \mathrm{m}^{-1} \cdot \mathrm{K}^{-1}$

$K_{m} \quad$ Mould metal thermal conductivity tensor

$\mathrm{W} \cdot \mathrm{m}^{-1} \cdot \mathrm{K}^{-1}$

$K_{a} \quad$ Air thermal conductivity tensor

$\mathrm{W} \cdot \mathrm{m}^{-1} \cdot \mathrm{K}^{-1}$

$L \quad$ Computational domain length

$\mathrm{m}$

$L_{f} \quad$ Melt front position

$\mathrm{m}$

$L_{m} \quad$ Mould thickness

$\mathrm{m}$

$L_{p} \quad$ Final polymer thickness

$\mathrm{m}$

$M_{p} \quad$ Mass of polymer

$\mathrm{Kg}$

$N \quad$ Number of elements of the mesh

$q \quad$ Heat flux

W. $\mathrm{m}^{-2}$

$S \quad$ Internal surface of the mould

$\mathrm{m}^{2}$

$t \quad$ time

S

$\begin{array}{lll}T & \text { Temperature field } & { }^{\circ} \mathrm{K}\end{array}$

$\begin{array}{lll}T_{a m b} & \text { Ambient temperature } & { }^{\circ} \mathrm{K}\end{array}$ 
$\begin{array}{lll}T_{\text {ext }} & \text { Temperature in the oven } & { }^{\circ} \mathrm{K}\end{array}$

$\begin{array}{lll}T_{f} & \text { Polymer melting point } & { }^{\circ} \mathrm{K}\end{array}$

x Spatial coordinate m

V Mould volume $\mathrm{m}^{3}$

$V_{p} \quad$ Volume of polymer $\quad \mathrm{m}^{3}$

$V_{a} \quad$ Volume of air $\quad \mathrm{m}^{3}$

$\begin{array}{lll}\rho_{p s} & \text { Solid polymer Density } & \mathrm{Kg} . \mathrm{m}^{-3}\end{array}$

$\rho_{p l} \quad$ Liquid polymer Density $\quad \mathrm{Kg} . \mathrm{m}^{-3}$

$\begin{array}{lll}\rho_{m} & \text { Mould metal density } & \mathrm{Kg} . \mathrm{m}^{-3}\end{array}$

$\rho_{a} \quad$ Air density $\quad \mathrm{Kg} \cdot \mathrm{m}^{-3}$ 